\begin{tabular}{c|c|c}
\hline \hline & CLIMATE RESEARCH & Published June 10 \\
Vol. 24: 59-70, 2003 & Clim Res & . \\
\hline
\end{tabular}

\title{
Examining the onset of spring in Wisconsin
}

\author{
Tingting Zhao ${ }^{1, *}$, Mark D. Schwartz ${ }^{2}$ \\ ${ }^{1}$ School of Natural Resources and Environment, 1520 Dana Building, 430 East University, University of Michigan, \\ Ann Arbor, Michigan 48109-1115, USA \\ ${ }^{2}$ Department of Geography, University of Wisconsin-Milwaukee, PO Box 413, Milwaukee, Wisconsin 53201-0413, USA
}

\begin{abstract}
Vegetation phenological events, such as bud break, flowering, and leaf coloring, are closely associated with lower atmospheric conditions as seasons change. Plant phenology during springtime is particularly sensitive to climatic factors, especially temperature variations. Therefore, the occurrence of specific plant events can be used to identify the onset of spring. Advance or delay in these timings can serve as potential climate change detection measures over long periods. In this paper, changes to spring's onset in Wisconsin were examined using the first-bloom event of several introduced and native species in 1965-1998. Due to the incompleteness of these observations, satellite data were applied to derive 3 phenological regions across the state. Next, average first-bloom time-series were formed at this regional scale. Several multi-species indices were then created based on regional first-bloom variations. Trends toward earlier first-bloom dates over the study period, especially for early-spring species, were revealed in the southwestern and central/eastern regions of Wisconsin. Two of the most important aspects of our study are: (1) phenology is regarded as a multispecies problem that can be more easily manipulated by reducing species variations to several indices; and (2) satellite data, weather data, and phenological observations are integrated to create and validate phenological regions, a process that can be used in other areas to facilitate long-term phenological data reconstruction.
\end{abstract}

KEY WORDS: Plant phenology $\cdot$ Climate change $\cdot$ Onset of spring $\cdot$ Remote sensing $\cdot$ Wisconsin

\section{INTRODUCTION}

Phenology, the study of seasonal plant and animal activity driven by environmental factors (Leith 1974, Schwartz 1998), has been applied to biological modeling and climate change measurement for decades (Cannell \& Smith 1983, Hunter \& Lechowicz 1992, Running \& Hunt 1993, Menzel \& Fabian 1999, Chuine 2000, Schwartz \& Reiter 2000). Plant events, such as budburst, leafing, and flowering, are well established to be highly associated with temperature variations at the beginning of spring (Schwartz \& Marotz 1986, 1988, Lechowicz 1995, Sparks \& Carey 1995, Beaubien \& Freeland 2000). Therefore, vegetation phenology is particularly useful in monitoring spring's arrival and its interannual variations. Earlier onset of spring over recent decades has been reported around the world based on long-term observations (Ahas 1999, Chmielewski \& Rötzer 2001, Menzel et al. 2001), simulated measures (Schwartz \& Reiter 2000), and satellite-based vegetation phenology (Moulin et al. 1997, Myneni et al. 1997, White et al. 1997).

However, 2 issues may prove problematic in monitoring spring onset shifts between years by means of plant phenology. First, phenological responses to identical climate change can vary among different kinds of species. Previous research has shown that, even for the same location and study period, different species often display dissimilar trends in spring phenology (e.g. Bradley et al. 1999, Menzel 2000). Some species appear to be more sensitive to climate variations, while others show little apparent connection with interannual climate differences. Unfortunately, few studies have explored the interrelations 
between multiple species events and spring climate variations.

Second, phenology has been observed only intermittently in most places around the world. Insufficient data collection limits efforts to compare species events across large geographical areas and over long time periods, and it complicates exploration of variations in spring's onset as measured by plant phenology. Although continental-scale simulation models have been developed based on selected species (Schwartz 1997), this approach alone cannot account for broader species diversity. Recently developed satellite metrics (e.g. Reed et al. 1994) have shown potential in monitoring the onset of spring across large areas, but the precise relationship between species-level phenology and remote-sensing imagery remains unclear. Therefore, an integrated approach, utilizing observational data, simulation models, and satellite imagery, is highly desired for phenological research (Schwartz 1994).

In this study, changes of spring's onset in Wisconsin will be assessed over the 1965-1998 period. The firstbloom events of several introduced and native species (which include herbs, shrubs, and trees) are examined as indicators of spring's arrival. Due to the incompleteness of the surface observations, satellite-derived startof-season (SOS) and modeled spring indices (SI) are employed to help reconstruct the first-bloom timeseries for different plant species. The onset of spring will thus be monitored through several integrated species first-bloom indices.

\subsection{Spring indices (SI): simulated phenology}

Observational data, collected over centuries in some European and Asian countries, have facilitated a better understanding of periodical species activity in relation to temperature changes (Fitter et al. 1995, Sparks \& Carey 1995, Spano et al. 1999). An earlier onset of spring since the late 1950s has been reported based on plant phenology from European networks (Menzel \& Fabian 1999, Menzel 2000). Similar trends were also detected in North America derived from simulated and actual phenology in 1959-1993 (Schwartz \& Reiter 2000).

One of the primary limitations for traditional phenological studies in North America is insufficient observations. As noted by Schwartz (1994), only a few indicator shrub species have geographically distributed phenological records, and most station data series are shorter than 20 yr. Given these conditions, simulation models based on past meteorological data become a necessary alternative for reconstructing missing phenological data. These 'rebuilt' data can be used to gauge the onset of the growing season and long-term climate change when weather data are available, but actual plant records do not exist (Schwartz \& Reiter 2000).

Using daily surface maximum and minimum temperatures, Schwartz \& Marotz (1986) developed regional phenological models for cloned lilac (Syringa chinensis 'Red Rothomagensis') first leaf across eastern North America. A better 'synoptic model' resulted in predictions within $7.5 \mathrm{~d}$ of actual leafing event occurrence. Schwartz \& Marotz (1988) reduced the prediction error by $1 \mathrm{~d}$ through development of the 'capstone model'. These models were next revised to create the spring index (average first-leaf date of 3 indicator species; Schwartz 1990) and finally were improved to form the spring indices (SI) that include first-leaf and firstbloom models (Schwartz 1997).

Based on favorable comparisons to coincident plant observations, SI models provide an effective way to generate accurate simulations of indicator and some native species phenology (Schwartz 1997, Schwartz \& Reed 1999). SI data were used to examine the variations of spring's onset across North America in 1900-1997 (Schwartz \& Reiter 2000). An average of 5 to $6 \mathrm{~d}$ advance toward earlier spring was detected through 1959-1993. Regional differences of warming associated with temperature variations were also found throughout North America. In a subsequent study, SI models were also applied in China, and they proved to be well-correlated with lilac events observed there (Schwartz \& Chen 2002).

\subsection{Start-of-season (SOS): remote-sensing metrics}

In parallel to modeled phenology, satellite imagery provides an alternative approach for phenological research. The most commonly used satellite measure is the normalized difference vegetation index (NDVI), typically processed from National Oceanic and Atmospheric Administration (NOAA) Advanced Very High Resolution Radiometer (AVHRR) data since 1982 (Schwartz 1999, Teillet et al. 2000).

Using the NDVI data, Goward et al. (1985) examined vegetation patterns in North America and demonstrated that the NDVI corresponded to known seasonality in the continental United States. Malingreau (1986) derived vegetation dynamics and crop patterns in Asia based on weekly AVHRR NDVI. The timing of onset and offset of the growing season was identified. Both studies show that the phenological behaviors of different broad vegetation types can be observed, analyzed, and mapped using NDVI multi-temporal profiles (Reed et al. 1994).

White et al. (1997) examined 8 deciduous broadleaf forest (DBF) and 5 grassland contiguous land-cover 
sites within the continental United States and southern Canada over the 1990-1992 period. They developed predictive phenology models based on satellite imagery, land-cover type, and meteorological data. The NDVI-based onset and offset of greenness for the DBF and grassland biomes in mid-latitudes were compared with lilac and native species phenology. Mean absolute error suggested that the satellite-based model predicted event dates within a week, on average. The satellite onset of greenness was strongly associated with temperature summations in both biomes.

Reed et al. (1994) created several satellite-based phenological metrics from 2 sets of satellite data: (1) AVHRR biweekly composite NDVI collected from 1989 to 1992 over the conterminous United States; and (2) land-cover data derived from the US Geological Survey (USGS) Earth Resources Observation System (EROS) Data Center. A systematic 1\% sample (every tenth row and tenth column) of the NDVI and landcover data was generated and computed for the data sets. Twelve seasonal metrics (including onset of greenness, time of peak NDVI, and maximum NDVI), which were closely connected to key phenological events, were developed. Central tendency and variability of these metrics were computed and analyzed for various land cover types (i.e. agricultural crops, grasslands, and forests). Strong coincidence was shown between the satellite-derived metrics and general phenological characteristics for different land cover types.

Schwartz \& Reed (1999) compared SOS with modeled SI phenology. Positive correlation was found between SOS and SI dates. Further research by Schwartz et al. (2002) compared the SOS data produced by the delayed moving average (DMA) technique of Reed et al. (1994) and the seasonal midpoint NDVI (SMN) method of White et al. (1997). Both satellite-derived data sets were correlated to SI phenology and observed native species bud break. According to the authors, SMN SOS dates occurred at roughly the same time as SI first bloom, while DMA SOS dates were about $40 \mathrm{~d}$ systematically earlier than SI dates. However, SMN SOS average bias errors were considerably higher than those of the DMA SOS, when both were compared to observed native species phenology. SI first bloom showed the best correlations with native species bud burst among the 3 predictive approaches, which under- lines the accuracy of SI simulations compared to satellite-based techniques.

\section{DATA}

Phenological data observations came from the Wisconsin Phenological Society (WPS) archives, which contain information on 62 plant species collected at about 250 observation stations across the entire state from 1962 to 1998. Species in the WPS program include 22 introduced plants and 40 native plants, covering a broad range of herbaceous and woody species.

First bloom is the most frequent event recorded for most of the plants. According to an initial data evaluation, over $99.5 \%$ of all observations were taken from 1965 to 1998. Nine species were rarely recorded, though listed in the WPS observational program. To facilitate long-term comparisons in this study, only 21 introduced and 32 native species were utilized in 1965-1998.

Further descriptive statistics showed that, despite statewide observations (Fig. 1), over $95 \%$ of the firstbloom time-series have more than $66 \%$ of their values missing throughout the study period. This means most

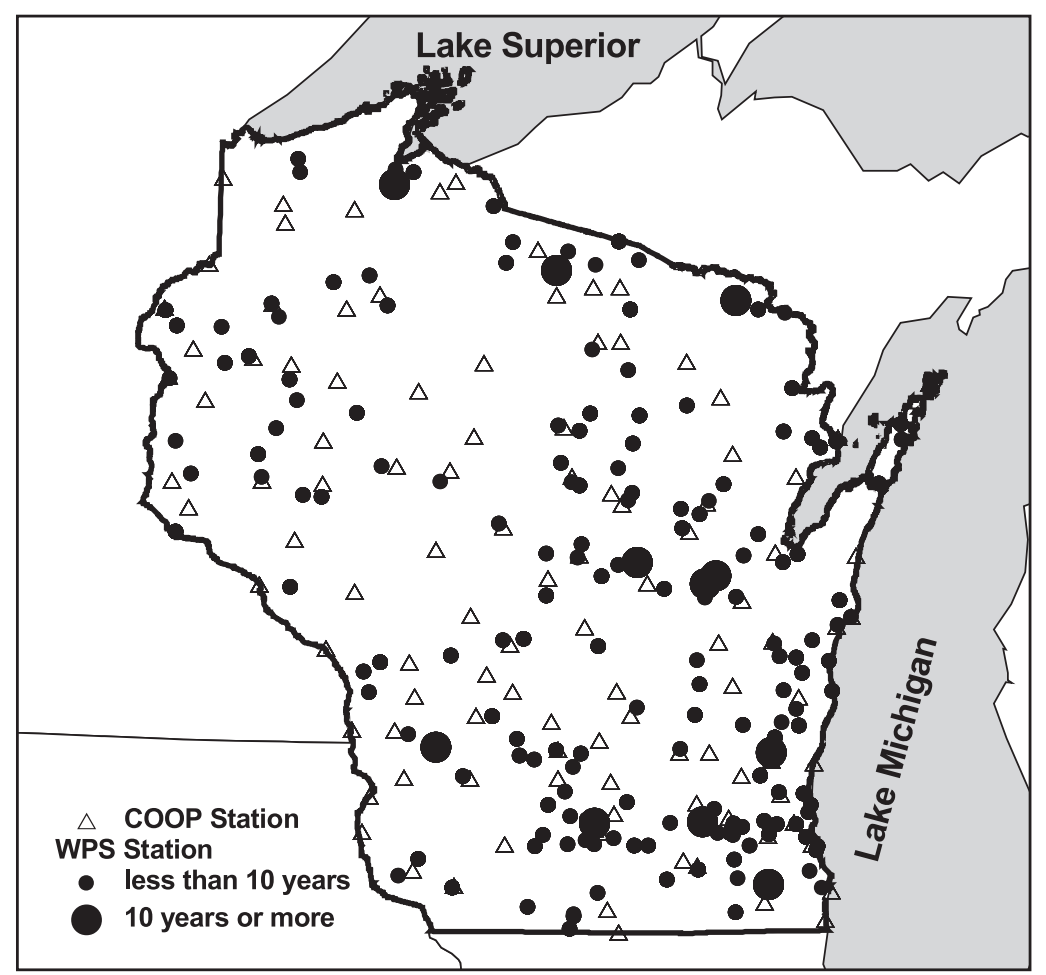

Fig. 1. Wisconsin Phenological Society Network stations and National Weather Service COOP weather stations. Despite statewide observations, only 11 phenological stations have more than 10 species observed for at least $10 \mathrm{yr}$ 
of the species events have been recorded for less than $12 \mathrm{yr}$ at each individual location. Only 11 stations have more than 10 species observed for at least $10 \mathrm{yr}$. The incompleteness of observational data greatly limits efforts aiming at long-term species comparisons at particular sites, let alone statewide study efforts.

Daily maximum-minimum temperature data, used to calculate SI first-bloom dates, were obtained from the Cooperative (COOP) Summary of Day CD-ROM data sets produced by the National Climatic Data Center (Ashville, NC). To enable comparisons of SI first-bloom timing at different geographical locations, weather stations at 108 sites that have maximum-minimum temperature records for at least 7 yr between 1990 and 1999 were selected. These weather stations are evenly distributed across the state (Fig. 1).

Remote-sensing data used to generate phenological regions in this study were yearly SOS date images during 1990-1993 and 1995-1999 (1994 was excluded due to satellite failure; Schwartz et al. 2002). These images were processed from biweekly composite NDVI data (produced by the USGS EROS Data Center) using the DMA technique (Reed et al. 1994) and kindly provided to us by Bradley Reed. Each image has a georeferenced $1 \mathrm{~km}$ pixel grid of SOS dates for the conterminous United States in a particular year.

\section{METHODS}

\subsection{Deriving phenological regions}

Nine yearly DMA SOS profiles (1990-1993 and 1995-1999) were statistically merged to create contiguous phenological regions in Wisconsin. Unsupervised classification was utilized in ERDAS IMAGINE (image-processing software) with 8-, 10-, 25-, and 50class solutions. Classification patterns were similar for the 10-, 25-, and 50-cluster schemes. Pixel frequency distribution of the classified images was close to a normal distribution in the 25- and 50-cluster cases. The 50 -class result was too fragmented to create broad regions. Therefore, based on image statistics, the 25class scheme was used as the basis for initial phenological regions within the state.

Six of the 25 classes account for more than $98 \%$ of the total area under analysis. Four of them are reasonably coherent in appearance and cover most of the terrestrial areas of Wisconsin. Accordingly, ignoring the tiny 'speckles' of embedded classes, 4 contiguous regions across the state were delineated manually (Fig. 2). Each of the so-derived regions is generally consistent with one of the DMA-SOS-based classes.

SI first-bloom dates, calculated from daily maximum-minimum temperature data at each weather station, were next used to examine the spatial variability of spring's onset within each satellite-based phenological region. Weather stations were separated into 4 groups according to the DMA SOS regions (Fig. 2). SI first-bloom time-series were then processed with 1-way ANOVA at stations where at least 6 yr of SI data were available in 1990-1993 and 1995-1999.

Mean comparisons showed that regional differences of the SI first bloom were significant at the $5 \%$ confidence level, except for Region 2. Region 2 could not be distinguished from Regions 1 and 3, but it was significantly different from Region 4 . Averages of the SI first-bloom dates at each weather station in Region 2 (Fig. 2) were computed and compared with the regional SI mean. The 4 stations with lower average SI (earlier first-bloom dates than Region 2 average) were merged into Region 1, while the 4 stations with higher average SI (later first-bloom dates than Region 2 average) were joined to Region 3. Adjusted phenological regions in Wisconsin were thus formed based on both the DMA SOS classification and the SI firstbloom calibration (Fig. 3). They were designated as the southwestern, central/eastern, and northern regions, respectively.

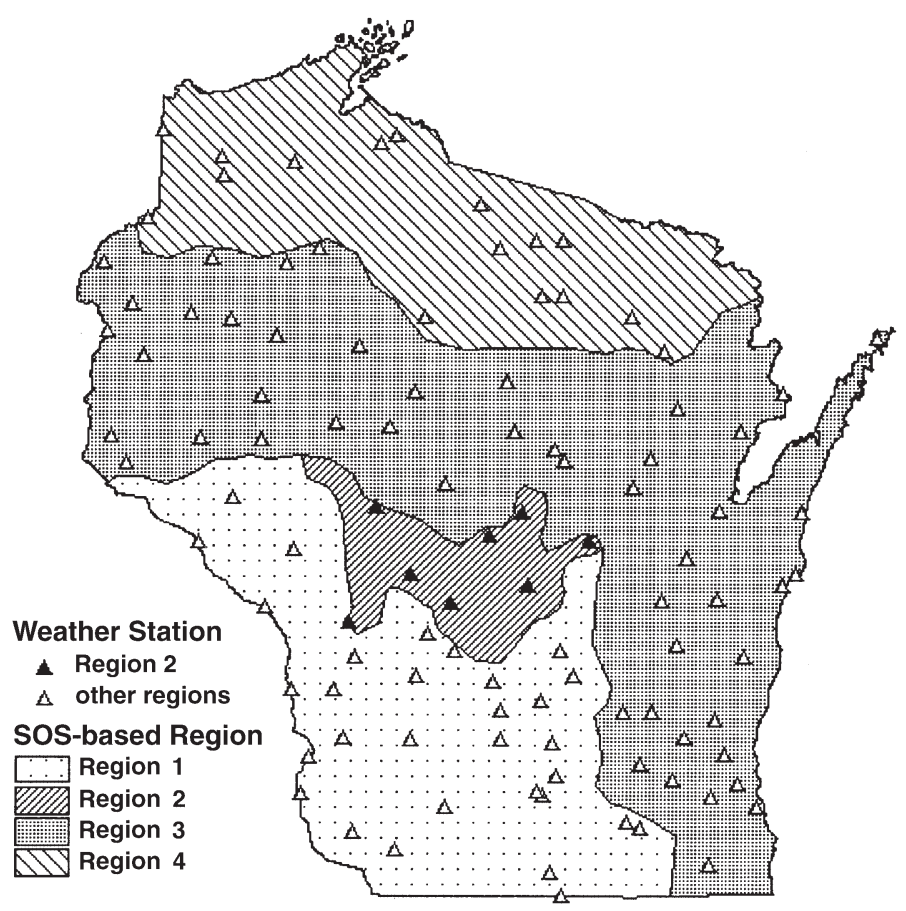

Fig. 2. DMA-SOS-based phenological regions. Four regions were generated based on classification of start-of-season (SOS) dates produced by the delayed moving average (DMA) technique. Weather stations used to calculate spring indices (SI) values are superposed onto these regions (those associated with Region 2 are highlighted using solid black triangles) 


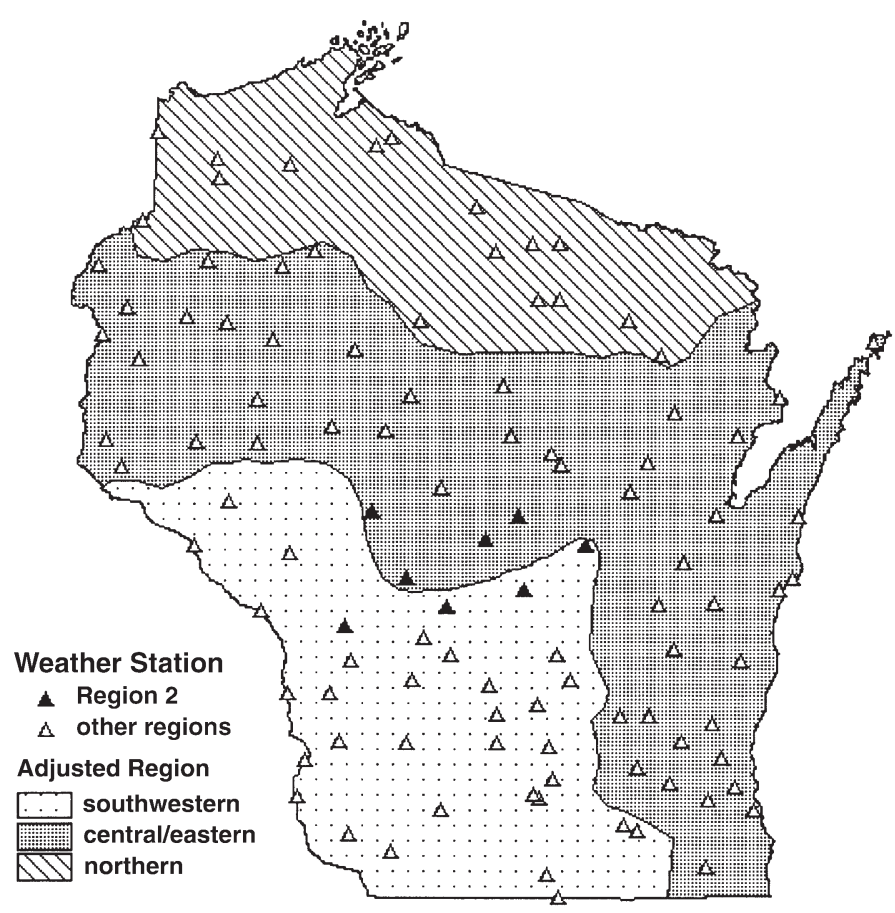

Fig. 3. Adjusted phenological regions in Wisconsin. Three regions were created based on classification of SOS data and examination of SI first-bloom dates. Weather stations marked with solid black triangles are the ones that associate with the former Region 2 (Fig. 2) before regional adjustment. They were separated into the southwestern and central/eastern regions based on their average SI values

\subsection{Reconstructing phenological data}

Assuming that intra-regional event timings are comparable for groups of species among different locations with similar general phenology and climate, each phenological region is now treated as a single observational 'site'. The averages of first-bloom dates from all intra-regional stations were thus designated as 'combined first-bloom' (CFB) values for each species in the corresponding region in 1965-1998. Missing values within the CFB time-series were still present due to the original data set characteristics. A species was discarded if its CFB sequence contained more than $10 \mathrm{yr}$ of missing data. Thus, only 14 native species and 12 introduced species (Table 1) were retained for subsequent analysis. These species all had at least $24 \mathrm{yr}$ of CFB data within the $34 \mathrm{yr}$ study period.

Next, hierarchical cluster analysis of the 26 species in each of the phenological regions produced species interrelationships in terms of CFB dates. Applying these clustering results, missing values in each species' CFB time-series were filled by 'boot strapping' interpolation from the most similar (and available) species in the same region. Data estimation started with species having the strongest correlation. For example, if one species was grouped into the same cluster as another, and the former had a complete ( $34 \mathrm{yr}$ ) set of CFB values, a linear regression model was run directly from the first species to fill the second species CFB timeseries. If 2 or more species were grouped into an identical cluster, but none of them had full time-series, then one was first restored (using regression) based on a complete species CFB time-series from the next-mostclosely correlated cluster. The 'restored' species timeseries then in turn filled in (again using regression) missing values of the other species in its own cluster. If a species was not part of any cluster and had missing values, the missing data were restored using regression based on the CFB time-series of all other species in the same region. When these analyses were complete, the fully reconstructed CFBs were validated by comparison with actual phenological records at 8 WPS stations with extensive data records.

\subsection{Creating integrated species indices (ISI)}

Integrated species indices (ISI), which represent the collective response of species with similar CFB variations, were created based on species intercorrelation in 1965-1998. Factor analysis (principal-components method) was applied to the fully reconstructed CFB time-series in each of the phenological regions. Multiple species were treated as variables to generate these condensed species indices measuring CFB date variations over the study period. Factors were retained only when their eigenvalues exceeded 1.

As a result, 3, 6, and 2 factors were created for the southwestern, central/eastern, and northern regions, respectively. Approximately $70 \%$ or more of the total variance of CFBs was explained by the 3 factors in the southwestern, the first 3 factors in the central/eastern, and both factors in the northern regions. Accordingly, species that greatly contributed (at least $65 \%$ from the rotated loadings) to any one of these major factors were selected to form the potential ISI.

To separate species similarities within a given factor, a cluster analysis of the fully reconstructed CFBs was run in each of the phenological regions. If the major contributing species to a given important factor formed an identical cluster, these species were treated as members of a final ISI. In contrast, if a group of species contributed to a given important factor about the same as another group did (and the former was placed into a different cluster than the latter), 2 distinct final indices were then formed even though both indices played a comparable role for the given factor. Thus, 3,4 , and 3 ISI were created for the southwestern, central/eastern, and northern regions, respectively (Table 2 ). 
Table 1. Species with relatively extensive combined first-bloom (CFB) timeseries

\begin{tabular}{|c|c|}
\hline Species common name & Species Latin name \\
\hline \multicolumn{2}{|l|}{ Native plants } \\
\hline Hepatica (sharp-lobed) & Anemone acutiloba (DC.) G. Lawson \\
\hline Bloodroot & Sanguinaria canadensis L. \\
\hline Dutchman's breeches & Dicentra cucullaria (L.) Bernh. \\
\hline Woods blue phlox & $\begin{array}{l}\text { Phlox divaricata L. subsp. laphamii } \\
\text { (A.W. Wood) Wherry }\end{array}$ \\
\hline Wild geranium & Geranium spp. \\
\hline True Solomon's seal & Polygonatum spp. \\
\hline Canada mayflower & Maianthemum canadense Desf. \\
\hline Pussy willow & Salix discolor Muhl. \\
\hline Silver maple & Acer saccharinum L. \\
\hline Red maple & Acer rubrum L. var. rubrum \\
\hline American elm & Ulmus americana L. \\
\hline Wild plum & Prunus americana Marshall \\
\hline Red osier dogwood & Cornus stolonifera Michx. \\
\hline Black elderberry & Sambucus canadensis L. var. canadensis \\
\hline \multicolumn{2}{|l|}{ Introduced plants } \\
\hline 'Asparagus shoots (height: 2")' & Asparagus officinalis L. \\
\hline Crocus & Crocus spp. \\
\hline Scilla & Scilla spp. \\
\hline Dandelion (not near buildings) & Taraxacum officinale \\
\hline Orange hawkweed & Hieracium aurantiacum L. \\
\hline Yellow sweet-clover & Melilotus officinalis (L.) Lam. \\
\hline White sweet-clover & Melilotus alba Medik. \\
\hline Alfalfa & Medicago spp. \\
\hline Canada thistle & Cirsium arvense (L.) Scop. \\
\hline Tawny daylily & Hemerocallis fulva (L.) L. \\
\hline Common lilac & Syringa vulgaris L. \\
\hline Spirea-bridal wreath & Spiraea spp. \\
\hline
\end{tabular}

ern, central/eastern, and northern regions, were generated based on both satellite and weather data. Mean SI first-bloom dates are $132.91 \pm 0.41$ for the southwestern region, $137.71 \pm 0.37$ for the central/ eastern region, and $144.57 \pm 0.69$ for the northern region. All regional means are significantly different at the $5 \%$ confidence level in terms of SI first-bloom timing. The increasing average values imply a logical progression of first-bloom timing from the southwest, through the central and east, and finally to the northern part of the state in 1990-1993 and 1995-1999.

Accuracy of the CFBs based on the so-derived phenological regions was tested by calculating standard errors of each multi-station CFB. The average standard error is $3.28 \mathrm{~d}$ for the southwestern, $3.58 \mathrm{~d}$ for the central/ eastern, and $3.19 \mathrm{~d}$ for the northern region. Up to $63.4 \%$ of CFBs in the southwestern region have a standard error of less than $3 \mathrm{~d}$, with $60.5 \%$ in the central/eastern, and $56.4 \%$ in the northern region.

Accuracy of the fully reconstructed CFBs (derived through multi-species regressions) was assessed in 2 ways:
Annual first-bloom dates of each integrated species index were calculated by averaging CFBs of the ISI member species. Therefore, firstbloom time-series were established for each of the ISI within each specific region. These ISI first-bloom dates and standard error values were plotted by phenological region (Fig. 4). Departures from average of the ISI firstbloom dates in 1965-1998 were also calculated. Lastly, linear trends of the departures were computed to derive regional first-bloom changes over the study period.

\section{RESULTS}

In this study 3 phenological regions in Wisconsin, namely the southwest-
Table 2. Integrated species indices (ISI) by phenological region

\begin{tabular}{|c|c|c|c|}
\hline Index & $\begin{array}{l}\text { Southwestern } \\
\text { region }\end{array}$ & $\begin{array}{c}\text { Central/eastern } \\
\text { region }\end{array}$ & $\begin{array}{l}\text { Northern } \\
\text { region }\end{array}$ \\
\hline 1 & $\begin{array}{l}\text { Scilla } \\
\text { Pussy willow }\end{array}$ & $\begin{array}{l}\text { Crocus } \\
\text { Scilla } \\
\text { Pussy willow }\end{array}$ & $\begin{array}{l}\text { Crocus } \\
\text { Scilla }\end{array}$ \\
\hline 2 & $\begin{array}{l}\text { Dandelion } \\
\text { Hepatica } \\
\text { Bloodroot } \\
\text { Dutchman's breeches }\end{array}$ & $\begin{array}{l}\text { Dandelion } \\
\text { Hepatica } \\
\text { Bloodroot } \\
\text { Dutchman's breeches } \\
\text { Red maple } \\
\text { American elm }\end{array}$ & $\begin{array}{l}\text { Dandelion } \\
\text { Bloodroot } \\
\text { Dutchman's breeches } \\
\text { Red maple }\end{array}$ \\
\hline 3 & $\begin{array}{l}\text { Common lilac } \\
\text { Spirea-bridal wreath } \\
\text { Woods blue phlox } \\
\text { Wild geranium }\end{array}$ & $\begin{array}{l}\text { Yellow sweet-clover } \\
\text { Common lilac } \\
\text { Spirea-bridal wreath } \\
\text { Woods blue phlox } \\
\text { Wild geranium } \\
\text { Wild plum } \\
\text { Red osier dogwood }\end{array}$ & Common lilac \\
\hline 4 & & $\begin{array}{l}\text { Orange hawkweed } \\
\text { Canada thistle }\end{array}$ & \\
\hline
\end{tabular}


(1) average mean absolute error of the predicted CFBs is $4.90 \mathrm{~d}$ for the southwestern, $4.67 \mathrm{~d}$ for the central/ eastern, and $4.32 \mathrm{~d}$ for the northern regions; and (2) when compared with actual data at 8 phenological stations across the state (these stations were selected as reference due to their extensive multi-species observations over at least $15 \mathrm{yr}$ ), average mean absolute error of the fully restored CFB dates is $2.73 \mathrm{~d}$ for the southwestern, $3.74 \mathrm{~d}$ for the central/eastern, and $2.50 \mathrm{~d}$ for the northern regions.

At the regional scale ISI were formed based on variance and correlation of the species CFBs. Species relationships were generally consistent among individual regions, although the total group of species studied in each region was different, due to data availability. For example, dandelion, hepatica, bloodroot, and Dutchman's breeches were grouped together in both of the southwestern and central/eastern regions. Though hepatica was not included in the northern region species data set, the other 3 species were categorized together in this region. The same was true for red maple, which was absent in the southwestern region, but was classified into the dandelion group in both the central/eastern and northern regions. To compensate for these uneven results, 4 standardized species-based indices were created (Table 2) for all of the phenological regions (although some member species were missing in some particular regions). Fig. 4 shows the ISI first-bloom time-series with \pm 1 standard error bars.

In the southwestern region (Fig. 4a), all Index-2 firstbloom dates are earlier than those of Index 3 by \pm 1 standard error in 1965-1998. First bloom of Index 1 appears to be earlier than that of Index 2; however, their standard errors overlap in some cases. In the central/eastern region (Fig. 4b), first bloom of Index 1 is the earliest, followed by Index 2, Index 3, and then Index 4. All of these indices' first-bloom dates can also be separated from one another by \pm 1 standard error. In the northern region (Fig. 4c), first bloom of Index 2 appears later than Index 1, but several cases of the 2 indices overlap within \pm 1 standard error. First bloom of Index 3 (consisting of only 1 species, common lilac) is the latest in this region.

Departures from the 1965-1998 average were calculated for each ISI first-bloom time-series. Variations of the ISI departures-from-average appear to be similar in most cases. Linear trends were then calculated for each departure sequence (Table 3). The assumption of independent, identically distributed residuals was

Fig. 4. Integrated species indices (ISI) first bloom by phenological regions. First-bloom dates (day of year, January $1=1$ ) of the ISI were calculated from the average of yearly member species' combined first blooms (CFBs) in the (a) southwestern, (b) central/eastern, and (c) northern regions
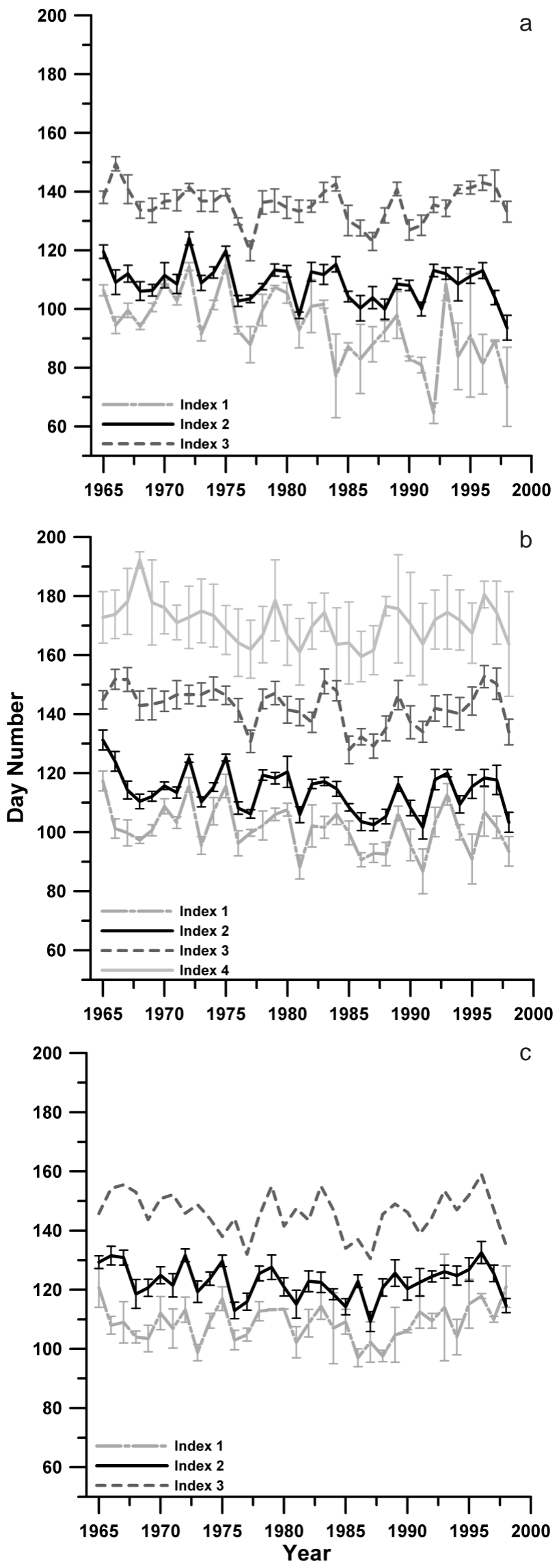
tested for each of the regressions of ISI first-bloom date against year. All of the residuals appear to be normally distributed on the normal probability plot of regression standardized residuals. Variance of the residuals also appears to be constant and close to 0 for all regressions, according to the scatterplot of regression standardized residuals against fits. The Durbin-Watson test for serial correlation of the residuals showed that all of the significant ISI first-bloom departure sequences (namely Indices 1 and 2 in the southwestern region and Index 2 in the central/eastern region) can be regarded as non-autocorrelated. No negative autocorrelations were found for the remaining departure timeseries.

Among the 10 indices only 1 displays a positive trend ( $0.06 \mathrm{~d} \mathrm{yr}^{-1}$ for Index 1 of the northern region), but it is not statistically significant. All of the other ISI firstbloom trends are negative. In the southwestern region, trends are all negative. Two of them (Indices 1 and 2) are significant at the $5 \%$ confidence level. The average trend (based on statistically significant trends) is $-0.46 \mathrm{~d} \mathrm{yr}^{-1}$ in this region. In the central/eastern region, the ISI first-bloom trends are also all negative. But only 1 (Index 2) is significant at the $5 \%$ confidence level. The trend is $-0.25 \mathrm{~d} \mathrm{yr}^{-1}$ in this region. In the northern region, 2 of the ISI first-bloom trends are negative, and 1 is positive. However, none of these trends is statistically significant.

\section{DISCUSSION}

\subsection{Validity of phenological regions and CFBs}

Three phenologically coherent regions were generated from the DMA SOS images coupled with the SI

Table 3. Integrated species indices (ISI) first-bloom linear trends (1965-1998). na: not applicable

\begin{tabular}{|clccc|}
\hline Index & $\begin{array}{c}\text { Phenological } \\
\text { region }\end{array}$ & $\begin{array}{c}\text { Average ISI first bloom } \\
\text { (day of year, Jan 1 = 1) }\end{array}$ & $\begin{array}{c}\text { Linear trend } \\
\left(\mathrm{d} \mathrm{yr}^{-1}\right)\end{array}$ & Significance \\
\hline \multirow{2}{*}{1} & Southwestern & 94.42 & -0.698 & 0.000 \\
& Central/eastern & 101.36 & -0.254 & 0.060 \\
& Northern & 108.92 & 0.062 & 0.572 \\
& Southwestern & 108.72 & -0.228 & 0.042 \\
& Central/eastern & 113.86 & -0.250 & 0.044 \\
& Northern & 122.77 & -0.083 & 0.419 \\
3 & Southwestern & 135.63 & -0.075 & 0.491 \\
& Central/eastern & 142.44 & -0.211 & 0.073 \\
& Northern & 145.93 & -0.107 & 0.395 \\
4 & Southwestern & na & na & na \\
& Central/eastern & 171.03 & -0.193 & 0.108 \\
& Northern & na & na & na \\
\hline
\end{tabular}

first-bloom dates in 1990-1993 and 1995-1999. The ANOVA test showed that averages of SI first bloom were significantly different among the 3 regions. To test intra-regional coherence of the SI first bloom, a $K$-means cluster analysis was applied to the $9 \mathrm{yr}$ SI first-bloom dates regardless of phenological region. We found that, although inter-regional differences of the SI first-bloom means were statistically significant, $33 \%$ of the stations failed to be consistent with their clustering-based regional membership when spatial attributes (i.e. latitude and longitude) were excluded. These discrepancies may have been caused by the distinctive approaches of satellite-based regionalization and temperature-based simulation (Schwartz et al. 2002).

Another possible reason for the questionable stations involves sacrificing detailed variations in the regionalizing process. To derive large coherent regions, tiny 'speckles' (generally smaller than $20 \times 20 \mathrm{~km}$ ) in the DMA SOS classification outcome were neglected and merged into the larger classes that geometrically contained the prior speckles. Several sizable classes were also discarded in the regionalization procedure. The rationale was: (1) they are obviously too small to represent regional patterns; and/or (2) either weather or phenological stations do not exist in such regions, which limit examination of their validity. In contrast to regional phenological patterns, stations at such locations may have different characteristics due to the varied microclimate.

Despite the ambiguous stations, phenological regions in our study depict a general provincial difference in Wisconsin regarding plant first-bloom events. Average SI first-bloom date increases from the southwestern to the northern region, indicating a later start of bloom events in the northern and eastern portions of the state. Such a timing progression reflects geophysical differences among regions. Location is no doubt responsible for the earlier timing of spring events in southern areas, since temperatures (associated with phenological timing) usually increase sooner in the south. Lake effect from Lake Michigan (Fig. 1) is likely responsible for the later start of first bloom in eastern areas, since temperatures near the lakefront are often lower than inland locations at the same latitude when land is warming up in spring.

The regional heterogeneity mirrored by our regionalization is broadly consistent with vegetation provinces based on ground survey (Curtis 1971). In his book The Vegetation of Wiscon- 
sin, Curtis divided Wisconsin into 2 distinct floristic provinces - the prairie-forest province in the southwestern part and the northern hardwoods province in the northeastern part. The provincial border zone in Curtis' research roughly overlaps the boundary between the southwestern and central/eastern regions in our study. This indicates that satellite-based regionalization can reflect phenological differentiation in terms of varied species composites. We also compared the regions with Kuchler's (1964) Potential natural vegetation of the conterminous United States. The southwestern region is approximately consistent with Kuchler's Oak Savanna. The central/eastern region is comparable to Kuchler's Northern Hardwoods and OakHickory Forest. The northern region generally covers Kuchler's Great Lake Pine Forest and Northern Hardwoods-Fir Forest. The well-behaved SI first-bloom sequence again seems to be broadly associated with natural ecological regions.

Regional first-bloom timing, i.e. CFBs derived from all intra-regional station averages, should be used with caution. CFBs eliminate many data vacancies in a particular species' time-series, as station sequences are joined to fill 'holes' in one another. However, some intra-regional diversity may then be lost in the soderived time-series. Distinctive stations fail to be distinguished from typical ones in the region, and eventually contribute to a regional average that may be biased by their participation.

Some potential causes of large CFB standard errors may include: (1) accidental taxonomic differences, which may happen if a common name is shared by different species from the identical genus; (2) false or erroneous records generated in the process of phenological observation or data transformation, such as converting paper-based records into digital data (Menzel et al. 2001); and (3) discrepancies in definition of species phenological phases by different observers (Schwartz \& Chen 2002).

In spite of all the uncertainties, more than half of the combination values have standard errors less than \pm 3 d. Moreover, compared with actual first-bloom data, up to $75 \%$ of the fully reconstructed CFBs have acceptable mean absolute errors of $4 \mathrm{~d}$ or less. Thus, the CFB data are fairly robust in representing intraregional phenological timing in terms of species first bloom.

\subsection{Changes of spring's onset in Wisconsin}

Different species' reactions to similar climate change over long periods have been well documented in many recent phenological studies (Sparks \& Carey 1995, Bradley et al. 1999, Menzel 2000, Menzel et al. 2001).
Sparks \& Carey (1995) found differing trends of spring phenology for a number of British species over 2 centuries (1736-1947). Earlier and delayed flowerings were both detected, with a typical earlier species being Anemone nemorosa (wood anemone) (-0.103 d yr $\left.\mathrm{y}^{-1}\right)$ and a later species being Brassica rapa (turnip) (0.097 $\left.\mathrm{d} \mathrm{yr}^{-1}\right)$. According to their study, flowering of $A$. nemorosa had a good correlation with monthly temperatures in January-May, while $B$. rapa bloom only associated with January-March temperatures at low $\mathrm{R}^{2}$. These results suggest that influences (e.g. photoperiod) other than temperature may have caused the delay of species flowering (Hunter \& Lechowicz 1992, Bradley et al. 1999).

In addition to determining the magnitude of different species trends, Menzel (2000) examined mean trend differences of several European species in 1959-1996. Different spring trends were found, but only Ribes alpinum differed significantly from all of the other species at the $5 \%$ confidence level. Menzel et al. (2001) studied spatial and temporal variability of phenological seasons in Germany from 1951 to 1996. They differentiated early and late spring species events, including flowering for 2 early species (Galanthus nivalis L. and Forsythia suspensa) and a late species (Malus domestica). Linear trends showed that all of these species had negative trends. However, the late species displayed less significant trends than the early ones.

Based on North American taxa, species in this study are not strictly comparable with the European genera. However, several similar relationships exist in varied species responses and different species correlations. Despite different species first-bloom timings, similar species time-series are identified and eventually bundled with reasonable confidence in each of our phenological regions. Most of the so-derived ISI have distinctive first-bloom dates from the other indices in the same region (Fig. 4). This implies that different species can be grouped together, according to their correlations in terms of first-bloom timing. The more similar the timing of intra-group species, the less the ISI first bloom varies.

ISI is capable of capturing the 'distilled' first-bloom characteristics of its member species, since crossregional comparison shows good correspondence of ISI succession. In all of the 3 phenological regions, indices from the crocus group (Index 1) usually have the earliest onsets of regional first bloom. Indices derived from the dandelion group (Index 2) always have earlier firstbloom timing than those composed of the common lilac group (Index 3).

Linear trends of the ISI first-bloom departures are only significant for less than one-third of the timeseries at the $5 \%$ confidence level. All of the statistically 
significant trends are negative in the southwestern and central/eastern regions. Index first-bloom trends are entirely negative in the southwestern region ( 2 of them have p-values less than 0.05), indicating earlier firstbloom timing in this region. Index first-bloom trends are all negative, but only 1 of them is significant at the $5 \%$ confidence level in the central/eastern region, suggesting that changes in first-bloom timing may not be very prominent in this region. In the northern region, 1 of the indices has a slightly positive trend, while the other 2 have slightly negative trends. None of these trends is statistically significant, which implies no overall trend changes in this region.

An interesting issue stems from the cross-regional coincidence of relations between the ISI succession and their first-bloom trends. 'Early spring' ISI (Index 2 in the southwestern and central/eastern regions, and Index 1 in the southwestern region) exhibit significant negative trends at the $5 \%$ confidence level in both of the southwestern and central/eastern regions in 1965-1998. Although 'late spring' ISI (Index 3 in the southwestern and central/eastern regions, and Index 4 in the central/eastern region) also display negative trends, none of them is statistically significant in both regions. These results suggest that first-bloom timing may shift toward earlier dates faster in the first part of spring than in the later part of spring in corresponding Wisconsin phenological regions over the study period. Thus, we should expect that most terrestrial areas of Wisconsin (except the northern region) have undergone an advancing onset of 'early season' spring (earliest arrival of warm weather) in 1965-1998.

Our findings coincide with the case study carried out in Fairfield Township, Sauk County, in southern Wisconsin (Bradley et al. 1999). In their paper, springtime events of 55 animal and plant species were examined during 2 time periods (1936-1947 and 1976-1998). Linear trends were projected across the entire $63 \mathrm{yr}$ time span, including the 28 yr data gap. Average timing dates and trends of timing were reported. Accordingly, about one-third of species events arrived significantly earlier over the period. Advancing event timing also appeared to occur more often in early months of spring, specifically in March. Sauk County is located in the southwestern region of our study, which also experienced significantly earlier onset of spring (especially in the early season) since the 1960s as shown in our results. Hepatica and Dutchman's breeches are the common species utilized in both research to calculate trends. Again the results are similar-negative trends were found for both species in both studies (hepatica was significant at $\mathrm{p}=0.05$ in their study), indicating earlier flowering in later years.

To test correlations between spring temperature variation and species event timing, regional tempera- ture trends were examined at COOP weather stations over the study period. No statistically apparent trends were detected in either annual or individual monthly (January-June) average temperatures of any region. A possible reason may be that temperature trends over the 34 yr study period are too subtle to be discerned from annual or monthly averages, due to strong daily temperature fluctuations (Bradley et al. 1999). However, species life cycles usually begin when certain thresholds are achieved (Schwartz \& Marotz 1986). Thus, plant phenology appears more capable than average temperatures to reflect subtle climate changes over long periods by reducing the 'noise' of short-term temperature variations.

\section{SUMMARY AND CONCLUSIONS}

In this work, spring's changing onset in Wisconsin was examined using plant phenology in 1965-1998. Species under study included 21 introduced and 32 native species which have been observed by volunteers across the Wisconsin Phenological Society (WPS) Network. These observational data alone proved insufficient for long-term and statewide studies due to their intermittent nature. Under these circumstances, start-of-season (SOS) and spring indices (SI) data were employed to generate phenologically coherent regions, which may maximize the potential usefulness of this incomplete data set.

The most important findings of this study include:

- Phenological regions, based on delayed moving average (DMA) SOS classification and SI first-bloom values, can reasonably represent general first-bloom progress in Wisconsin.

- Combined first-bloom (CFB) values, reconstructed from intra-regional stations' averages and speciesbased regressions, can represent regional collective first-bloom characteristics with acceptable absolute errors.

- Species similarity exists in all phenological regions. Based on species correlations, integrated species indices (ISI) can be created to condense the extensive species diversity to a more manageable level.

- Changes of regional first-bloom timing varied among phenological regions in Wisconsin from 1965 to 1998. First bloom in the southwestern and central/eastern regions appears to move toward earlier arrival over the period, especially for early-season species. The advance of spring's onset is about $0.46 \mathrm{~d} \mathrm{yr}^{-1}$ for the southwestern and $0.25 \mathrm{~d} \mathrm{yr}^{-1}$ for the central/eastern region.

In regard to these findings, several potential problematic issues were noted, including: (1) validity of regionalization based on satellite SOS and SI simula- 
tion, (2) confidence that CFBs represent general regional timing, and (3) risks of extending the study period backward to the mid-1960s, since phenological regions were based on the last decadal SOS and SI data. In future research, efforts should focus on reducing these uncertainties to improve validity of the species-based indices. Several relevant issues not emphasized here, but attractive for future work, include: (1) matching up phenological regions and multi-species indices at the state-scale across the US, (2) phenological regionalization at multiple geographic scales, and (3) expanding multi-species indices to cover broader species diversity. An enhanced national phenological network and institutional cooperation are critically needed to fulfill these potential research goals.

In general, the scheme of regionalization devised in this study should facilitate long-term, statewide phenological studies. At the regional scale, species correlations may be helpful in creating integrated indices, which can represent common trends of species event timing in different springtime periods over long time spans. Changes in the onset of spring can therefore be monitored through variations of the species-based indices. Integrated approaches to the use of satellitederived SOS, SI simulation phenology, and surface phenological observations have proven effective in monitoring spring's onset across Wisconsin. These techniques should also be useful in extending understanding of springtime changes in other mid-latitude locations around the world, with similar problematic phenological data sets.

Acknowledgements. The authors wish to thank the many Wisconsin Phenological Society volunteers who provided precious data for this study. Thanks also to B. C. Reed, who kindly provided the SOS data, and to G. G. Fredlund and J. Albrecht, who gave many insightful suggestions during the research procedure. This paper is based upon work supported by the National Science Foundation under Grant nos. ATM-9809460 and ATM-0085224.

\section{LITERATURE CITED}

Ahas R (1999) Long-term phyto-, ornitho- and ichthyophenological time-series analyses in Estonia. Int $\mathrm{J}$ Biometeorol 42:119-123

Beaubien EG, Freeland HJ (2000) Spring phenology trends in Alberta, Canada: links to ocean temperature. Int J Biometeorol 44:53-59

Bradley NL, Leopold AC, Ross J, Huffaker W (1999) Phenological changes reflect climate change in Wisconsin. Proc Natl Acad Sci USA 96:9701-9704

Cannell MGR, Smith RI (1983) Thermal time, chill days and prediction of budburst in Picea sitchesis. J Appl Ecol 20: 951-963

Chmielewski FM, Rötzer T (2001) Response of tree phenology to climate change across Europe. Agric For Meteorol 108: $101-112$
Chuine I (2000) A unified model of budburst of trees. J Theor Biol 207:337-347

Curtis JT (1971) The vegetation of Wisconsin. University of Wisconsin Press, Madison

Fitter AH, Fitter RSR, Harris ITB, Williamson MH (1995) Relationships between first flowering date and temperature in the flora of a locality in central England. Funct Ecol 9: $55-60$

Goward SN, Tucker CJ, Dye DG (1985) North American vegetation patterns observed with the NOAA-7 Advanced Very High Resolution Radiometer. Vegetatio 64:3-14

Hunter AF, Lechowicz MJ (1992) Predicting the timing of budburst in temperate trees. J Appl Ecol 29:597-604

Kuchler AW (1964) Potential natural vegetation of the conterminous United States. Special Publication No. 36, American Geographical Society, New York

Lechowicz MJ (1995) Seasonality of flowering and fruiting in temperate forest trees. Can J Bot 73:147-148

Lieth H (1974) Phenology and seasonality modeling. Springer-Verlag, Berlin

Malingreau JP (1986) Global vegetation in dynamics: satellite observations over Asia. Int J Remote Sensing 7:1121-1146

Menzel A (2000) Trends in phenological phases in Europe between 1951 and 1996. Int J Biometeorol 44:76-81

Menzel A, Fabian P (1999) Growing season extended in Europe. Nature 397:659

Menzel A, Estrella N, Fabian P (2001) Spatial and temporal variability of the phenological seasons in Germany from 1951 to 1996. Global Change Biol 7:657-666

Moulin S, Kergoat N, Viovy N, Dedieu G (1997) Global-scale assessment of vegetation phenology using NOAA/AVHRR satellite measurements. J Clim 10:1154-1170

Myneni RB, Keeling CD, Tucker CJ, Asrar G, Nemani RR (1997) Increased plant growth in the northern high latitudes from 1981 to 1991. Nature 386:698-702

Reed BC, Brown JF, VanderZee D, Loveland TR, Merchant JW, Ohlen DO (1994) Measuring phenological variability from satellite imagery. J Veg Sci 5:703-714

Running SW, Hunt ER (1993) Generalization of a forest ecosystem process model for other biomes BIOME_BGC and an application for global scale models. In: Field C, Ehleringer J (eds) Scaling physiological processes, leaf to globe. Academic Press, New York, p 144-157

Schwartz MD (1990) Detecting the onset of spring: a possible application of phenological models. Clim Res 1:23-29

Schwartz MD (1994) Monitoring global change with phenology: the case of the spring green wave. Int J Biometeorol 38:18-22

Schwartz MD (1997) Spring index models: an approach to connecting satellite and surface phenology. In: Lieth $\mathrm{H}_{\text {, }}$ Schwartz MD (eds) Phenology of seasonal climates. Backhuis, Leiden, p 23-38

Schwartz MD (1998) Green-wave phenology. Nature 394: 839-840

Schwartz MD (1999) Advancing to full bloom: planning phenological research for the 21st century. Int J Biometeorol 42:113-118

Schwartz MD, Chen X (2002) Examining the onset of spring in China. Clim Res 21:157-164

Schwartz MD, Marotz GA (1986) An approach to examining regional atmosphere-plant interactions with phenological data. J Biogeogr 13:551-560

Schwartz MD, Marotz GA (1988) Synoptic events and spring phenology. Phys Geogr 9(2):151-161

Schwartz MD, Reed BC (1999) Surface phenology and satellite sensor-derived onset of greenness: an initial comparison. Int J Remote Sensing 20:3451-3457 
Schwartz MD, Reiter BE (2000) Changes in North American spring. Int J Climatol 20:929-932

Schwartz MD, Reed BC, White MA (2002) Assessing satellitederived start-of-season measures in the conterminous USA. Int J Climatol 22:1793-1805

Spano D, Cesaraccio C, Duce P, Snyder RL (1999) Phenological stages of natural species and their use as climate indicators. Int J Biometeorol 42:134-138

Sparks TH, Carey PD (1995) The responses of species to cli-

Editorial responsibility: Robert Davis,

Charlottesville, Virginia, USA mate over two centuries: and analysis of the Marsham phenological record, 1936-1947. J Ecol 83:321-329

Teillet PM, El Saleous N, Hansen MC (2000) An evaluation of the global 1-km AVHRR land dataset. Int J Remote Sensing 21:1987-2021

White MA, Thornton PE, Running SW (1997) A continental phenology model for monitoring vegetation responses to interannual climatic variability. Global Biogeochem Cycles 11:217-234

Submitted: December 6, 2002; Accepted: February 25, 2003 Proofs received from author(s): May 23, 2003 